\title{
A NEW RE-ACTION FOR THYMOL OR PHENOL.
}

[By Prof. J. F. Exkman, Torro, Japan.]

If a small crystal of thymol is dissolved in about 1 cubic centimeter of glacial acetic acid, and this solution mixed with about one-fifth its volume (5 to 6 drops) of concentrated sulphuric acid, a fine blue colour is produced by allowing one drop of nitric acid to flow down to the bottom of the test-tube. On shaking, the whole liquid acquires this blue colour. In presence of not too small a quantity of thymol, the liquid appears dichroic, being red by transmitted, and dark blue by reflected, light.

Phenol differs from thymol, in this re-action, by causing the appearance of a fine violet red colour.

Salicylic acid, menthol, camphol, and borneol give no colour re-action under the above conditions.-American Druggist. 
Ilumminating Gas from Fermenting Mandre.-M. Gayon has demonstrated to the Paris Académie des Sciences the possibility of obtaining flluminating gas in considerable quantity from the fermentation of cow and horse droppings. This material is subject to fermentations of different orders, accordingly as it is kept in a close receptacle or allowed free access of air. In the latter case its temperature rises rapidly, and there is a great evolution of carbonic acid; while in the former the temperature remains fairly constant, and there is an active production of carburetted hydrogen, mixed with carbonic acid. The evolution of carburetted hydrogen is ascribed to the agency of organisms infinitely small, but differing in kind from those found in aërated manure. These have been isolated, and have been observed to occasion the evolution of the same gases from pure cellulose. The carburetted hydrogen disengaged from fresh manure Irept in a close box, one meter square, has been collected by M. Gayon and burnt before a scientific society at Bordeaux. The volume of carburetted hydjogen given off by 1 cubic meter of fresh horse droppings is about 100 liters, or 3.53 cubic feet, per twenty-four hours. M. Pasteur suggests that as this method of preserving manure in olose storage retains ammonia, it is possible that in certain circumstances it might be utilised for the purpose of supplying a useful heating and lighting gas without injury to the value of the fertilizer.-Scientifio American.

Trx annual report of Mr. B. F. Davenport, Vinegar Inspector of Boston, shows a decided improvement in the quality of that article during the year ending April, 1884. In 68 cases the inspector has sent a " note of warning" to the dealer, which, in most instances, was all that was necessary to remedy the evil. In a few cases prosecutions have been instituted for violation of the law. The standard is fixed at 5 per cent. by weight of absolute acetic acid, and for cider-vinegar, a residue of not less than 1.5 per cent. of solids. The report gives the method employed for determining the acidity and solid residue of a vinegar.

\section{LAW REPORTS.}

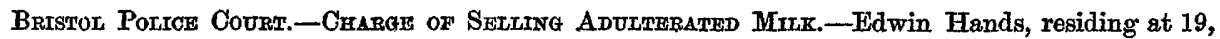
Christmas Street, was summoned for selling $1 \frac{1}{2}$ pints of milk, the same being adulterated. $M r . R$. Wansbrough appeared for the defendant. Police-Inspector Cooper, $C$ Division, stated that he purchased the $1 \frac{1}{3}$ pints of millk, and told defendant it was for analysis. He produced the certificate of the city analyst, which showed that the milk was adulterated to the extent of eight per cent. of added water. Mr. Wansbrough drew the attention of the magistrates to the well-known fact that water was found in milk, and that the quality varied in two different milkings from the same animal. He quoted a ease reported in the "Justice of the Peace," showing that an officer from Somerset House submitted a sample of milk which he had himself drawn from the cow, which was found to contain $7 \frac{1}{2}$ per cent. of water. The Bench were not satisfied that the water proved to be in the milk was added water, and dismissed the case.

\section{RECENT CHEMICAL PATENTS.}

The following specifications have been recently published, and can be obtained from the Great Seal Office, Cursitor Street, Chancery Lane, London

No. Name of Patentee.

1479 T. Venables .. ...

.. Purifying the Spent Lyes formed during the Manufacture of Soap, and the Production of Iiquor from which

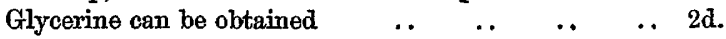

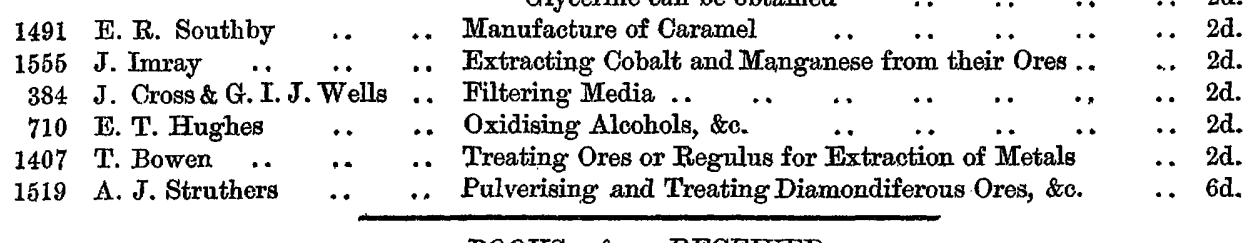
BOOKS, \&c., RECEIVED.

The Chemist and Druggist; The Brewers' Guardian; The British Medical Journal; The Pharmaceutical Journal; The Sanitary Record ; The Miller ; The Provisioner; The Practitioner ; New Remedies; Proceedings of the American Chemical Society; The Inventors' Record; New York Public Health; The Scientific American; Society of Arts Journal; Sanitary Engineer of New York; Cowkeeper and Dairyman's Journal; Sugar Cane; Country Brewers' Gazette; The Medical Record; The Grocers' Gazette; London Water Supply, by Crookes, Odling and Tidy; Ohemical Review ; Independent Oil and Drug Joumal and Paint Review; Science Monthly ; Jonrnal of the Society of Chemical Industry. 